\title{
热带生物海岸保护与发展研究
}

\author{
张乔民 ${ }^{1,2}$ ，杨红强 ${ }^{1,2}$ ，赵美霞 ${ }^{1,2}$, 张偲 ${ }^{1,2}$ \\ (1. 中国科学院南海海洋研究所, 广州 510301；2. 中国科学院南海生态环境工程创新研究院, 广州 510301)
}

\begin{abstract}
摘要：热带生物海岸是对海岸带生物多样性和资源生产力有特别价值的生物活动高度集中的海岸生态关键区。人类世自然环 境的快速变异和海岸带人类活动的持续增强使得海岸带生态安全和可持续发展受到前所未有的挑战。本文详细介绍了生物海 岸的研究现状和进展, 以及当前所面临的生态风险, 提出保护发展生物海岸的政策性建议, 包括加强国家战略规划, 节能减 排, 严控开发, 保护优先, 维持和增强抗全球变化干扰和自然恢复能力; 完善监测网络和开展全面调查; 加强科学管理和建 立远海大型海洋保护区; 加强科学研究和人才培养。国家建设海洋强国的战略决策和南海岛礁工程的顺利实施, 为我国珊瑚 礁研究提供了空前的发展机遇, 前景可期。
\end{abstract}

关键词: 生物海岸; 珊瑚礁; 红树林; 生态关键区; 人类世

中图分类号：P74 文献标识码：A

\section{Protection and Development of Tropical Biological Coasts}

\author{
Zhang Qiaomin ${ }^{1,2}$, Yang Hongqiang ${ }^{1,2}$, Zhao Meixia ${ }^{1,2}$, Zhang Si ${ }^{1,2}$ \\ (1. South China Sea Institute of Oceanology, Chinese Academy of Sciences, Guangzhou 510301, China; 2. Innovation Academy of \\ South China Sea Ecology and Environmental Engineering, Chinese Academy of Sciences, Guangzhou 510301, China)
}

\begin{abstract}
Tropical biological coasts are ecologically critical areas with high concentration of biological activities, which is of special value to the biodiversity and resource productivity of coastal zone. The rapid environmental fluctuation and enhanced human activities in the Anthropocene have risked the ecological security and sustainable development of the coastal zone. This paper mainly focuses on the research progress and ecological risks of the biological coasts, and proposes some suggestions on their protection and management, including: reinforcing national strategic planning to save energy, reduce emissions, strictly control the exploitation, and give priority to protection, thereby maintaining and enhancing natural resilience; improving the monitoring network while conducting a comprehensive survey; promoting scientific management and establishing large offshore marine protected areas; and strengthening scientific research and personnel training. The national strategy of building a maritime power and the implementation of the island and reef engineering project in the South China Sea provide unprecedented opportunities for the study of coral reefs in China, with promising prospects.
\end{abstract}

Keywords: biological coasts; coral reefs; mangroves; ecologically critical areas; Anthropocene

收稿日期 : 2019-07-15; 修回日期 : 2019-10-12

通讯作者: 张偲, 中国科学院南海海洋研究所研究员, 中国工程院院士, 研究方向为海洋生物学、海洋生物技术和海洋生态学; E-mail:zhsimd@scsio.ac.cn

资助项目 : 中国工程院咨询项目 “海洋强国战略研究 2035” (2018-ZD-08); 中国科学院南海生态环境工程创新研究院自主部署资助项目 (ISEE2018PY01)

本刊网址 : www.engineering.org.cn/ch/journal/sscae 


\section{一、前言}

我们通常可根据塑造海岸的主导因素和海岸的 物质组成来划分海岸，其中生物海岸在潮间带或潮 下浅水区生长有相当规模的底栖生物群落, 其生物 过程对海岸发育显著影响或成为主导因素 [1]。珊 瑚礁海岸和红树林海岸是典型的热带生物海岸。生 物海岸强调研究海岸动力地貌过程与生物过程之 间的双向相互作用, 或称之为海岸生物地貌学 [2]。 生物地貌过程是海岸生态系统响应和反馈全球变化 的主要机制之一 [3]。热带生物海岸的特殊生物栖 息环境往往成为对维持海岸带生物多样性和资源生 产力有特别价值的各种生物活动高度集中的海岸生 态关键区 [4]。它具有十分重要的生态系统服务功 能, 包括海岸高生物多样性、高资源生产力、海岸 抗侵蚀和稳定、净化和美化环境 [5]。海岸带又面 临人类世自然环境快速变异和海岸带人类活动持续 增强等问题, 海岸带生态安全和可持续发展受到更 大挑战。热带生物海岸中的珊瑚礁和远海岛礁, 对 海洋国土、海洋维权、海洋强国建设关系尤其密切 而受到特别关注。

\section{二、世界典型热带生物海岸的现状与特征}

\section{（一）世界珊瑚礁海岸的现状与特征}

珊瑚礁海岸是由造礁石珊瑚群落原地碳酸盐骨 骼和各种生物碎屑充填胶结共同形成的具有抗浪性 能的海底隆起结构 [6]。珊瑚礁是地球上仅仅由动 植物建造的最大地质地貌体, 其中有许多从太空中 都可以清楚地看到。珊瑚礁生态系统初级生产力非 常高, 具有地球生态系统中最活跃的钻化过程, 碳 酸钙年总产量约为 $9.29 \times 10^{9} \mathrm{t}[7]$ 。珊瑚礁海岸生物 多样性很高, 常被称为海洋热带雨林。全球珊瑚礁 主要分布在冬季水温始终高于 $18{ }^{\circ} \mathrm{C}$ 的印度洋 -太 平洋、加勒比海和红海的热带浅水区 [8]。

进入人类世新时期的海岸带在人口密度和开发 活动不断增强及全球环境变化不断加速的双重影响 下, 珊瑚礁的世界性退化越来越显著, 形势越来越 严峻 $[9,10]$ 。1970 年以来, 珊瑚礁白化愈发普遍和 严重 [11], 珊瑚礁的干扰由传统的间断性、事件性 逐步转变为持续性、趋势性, 破坏力和恢复力之间 的平衡受到破坏 [12]。由此导致各大礁区活珊瑚覆
盖率连续下降, 印度洋 - 太平洋区下降了 $40 \%$, 大 堡礁和西大西洋区下降了 50\% 53\% [13]。全球珊 瑚礁监测网络和美国世界资源研究所 1998 年以来 分别提出系列评估报告, 前者 2008 年报告认为受 到中等及以上破坏的珊瑚礁已经达到全球珊瑚礁面 积的 54\% [14], 后者 2011 年报告认为受到中等及 以上威胁的珊瑚礁已经达到全球珊瑚礁面积的 $61 \%$ 到 75\%（后者加上全球变化的影响）[15]。珊瑚礁 已经形成全球性衰退趋势, 其中澳大利亚最轻微, 东南亚最严重 [10]。

大堡礁是世界上规模最大的珊瑚礁生态系统, 1975 年成立海洋公园, 管理范围为 $3.444 \times 10^{5} \mathrm{~km}^{2}$, 延伸 $2600 \mathrm{~km}$, 包括 2900 个礁体和 900 多个礁岛。 在相当长一段时间内是世界面积最大和保护管理最 好的珊瑚礁保护区。1981 年被列入世界自然遗产 名录。2004 年澳大利亚议会把大堡礁完全保护区 (NTAs) 面积从 1981 年确定的 5\% 扩大到 33\% [9]。 2005 年澳大利亚研究委员会 (ARC) 成立珊瑚礁 卓越研究中心 ( CoECRS), 对珊瑚礁管理和可持 续利用进行综合研究。尽管如此, Bellwood 等 [16] 根据历史数据分析, 认为过去 40 年中大堡礁活珊瑚 平均覆盖率由 $40 \%$ 下降到 $20 \%$ 。De'ath 等 [17] 根据 1985-2012 年对 214 个珊瑚礁的 2258 次调查监测资 料分析, 其平均覆盖率由 $28.0 \%$ 下降到 $13.8 \%$, 驱 动因子热带气旋占 $48 \%$, 长棘海星侵害占 $42 \%$, 白 化占 $10 \%$ 。针对大堡礁活珊瑚平均覆盖率不断下降 和新的海岸开发及港口疏浚等计划的严重威胁, 联 合国世界遗产委员会 2012 年发出将大堡礁 “列入 濒危遗产名录” 的警示, 引起政府和科学界的广范 关注。澳大利亚政府斥资 1 亿澳元制定的 “大堡礁 2050 保护计划”, 承诺改善水质、禁止挖泥船倾倒、 限制沿岸港口发展。2015 年该计划得到认可而决定 不将大堡礁列入濒危遗产名录。在 2015-2016 年第 三次全球性珊瑚白化事件期间, 澳大利亚 CoECRS 主任 Terry P. Hughes 亲自乘飞机监测大堡礁珊瑚礁区 的白化情况并被新闻界广泛关注, 2016年 12 月被《自 然》杂志评为全球十大科学人物之一, 授予 “珊瑚 礁哨兵” 称号 [18]。

\section{（二）世界红树林海岸现状与特征}

红树林海岸以其潮间带平均海平面以上生长 的称为红树林的茂密耐盐常绿乔木或灌木为其基 
本特征 [19]。经统计，1997 年全球红树林面积约 为 $1.8 \times 10^{5} \mathrm{~km}^{2}$ [20], 不到世界热带森林资源面 积的 $2 \%$ 。南亚和东南亚占 $41.5 \%$ 。印度尼西亚占 $23 \%$ [20]。世界红树林最大连续分布区位于孟加拉 湾的恒河三角洲, 面积超过 $6000 \mathrm{~km}^{2}$ 。最近的卫星 遥感调查表明, 红树林向水产养殖、农业和城市发 展的转变是全球红树林破坏的主要原因 $[20,21]$ 。自 1950 年以来, 由于生态环境保护不够和大规模转化, 全球近 50\% 的红树林生物群落已经消失 [22]。如果 红树林按照 1980-2000 年的损失率（1\% 2\%）继 续下去, 整个红树林生物群落可能将在未来 100 年 内消失 [23]。2004 年的印度洋海啸事件和 2008 年的 《蓝碳报告》成为红树林保护海岸和减缓及适应气候 变化方面重要性认识的分水岭, 红树林恢复项目获 得国际关注和广泛支持 [24]。在 70 个拥有红树林的 国家中, 大多数国家都在实施恢复计划 $[20]$ 。但除 了以木材生产为主要目标的恢复项目效果较好之外, 其他恢复项目并没有取得普遍的成功 [25]。但总体 上红树林损失速率在明显降低。最近通过遥感方法 统计，2000-2012 年全球红树林面积平均年损失率 约为 $0.16 \%$, 比 1980-2000 年的损失率低了一个 数量级 [26]。

\section{三、我国热带生物海岸的现状与特征}

\section{（一）我国珊瑚礁海岸的现状与特征}

中国珊瑚礁分岸礁和环礁两大类, 岸礁断续分 布在海南岛、台湾岛和雷州半岛西南角等海岸区; 环礁广泛分布在南海, 128 个环礁组成南海诸岛岛 礁的基础。按照地貌类型范围统计其总面积约为 $3 \times 10^{4} \mathrm{~km}^{2}$, 约占全球珊瑚礁总面积的 5\% [1]。128 个 环礁中面积约占 $5 / 6$, 个数约占一半的为沉没型珊 瑚礁体 (如中沙大环礁、礼乐滩大环礁等), 其余 面积约占 $1 / 6$ 的为干出型珊瑚礁体, 在大潮低潮时 可露出礁坪, 礁坪总面积约为 $907 \mathrm{~km}^{2}$, 环礁潟湖 总面积约为 $4380 \mathrm{~km}^{2}$, 礁坪上的自然岛屿沙洲共 53 个, 总面积约为 $12 \mathrm{~km}^{2}$ 。中国南海珊瑚礁的重 要特点就是岛屿沙洲偏少偏小, 沉没型珊瑚礁广泛 分布 [1]。南海诸岛珊瑚礁岛屿、沙洲、礁坪和潟 湖区是我国海洋国土重要的标志和依据, 也是远海 渔业活动和其他海事活动的重要基地 [1]。
2002 年美国世界资源研究所利用 $1 \mathrm{~km}^{2}$ 网格量计 算浅水区近表层礁面积, 其中中国大陆为 $900 \mathrm{~km}^{2}$, 中 国台湾为 $700 \mathrm{~km}^{2}$, 西沙群岛和南沙群岛为 $5700 \mathrm{~km}^{2}$, 合计为 $7300 \mathrm{~km}^{2}$, 占世界总面积的 $2.57 \%$ [27]。在占 面积比例大于 $1 \%$ 的 21 个国家中，位列第 8 , 在印 度尼西亚、澳大利亚、菲律宾、法国、巴布亚新几 内亚、斐济、马尔代夫之后 [28]。中国南海诸岛珊 瑚礁对海洋国土资源和海洋权益维护有特殊重要意 义, 远海岛礁对海洋强国建设关系尤其密切。我国 珊瑚礁调查研究、监测评估和管理保护亟需加强。

\section{（二 ）我国红树林海岸的现状与特征}

中国红树林断续分布于东南沿海热带、亚热 带海岸的港湾、河口湾等受掩护水域。从海南岛向 北, 随着纬度升高, 气候带由中热带、北热带、南 亚热带到中亚热带, 红树林分布面积和树种数降低, 林相由乔木变为灌木, 树高和调落物产量降低, 充 分显示温度的宏观控制。其中万亩 $\left(6.67 \mathrm{~km}^{2}\right)$ 以 上连片分布区有海南清澜港、东寨港, 广西珍珠 港, 广东雷州湾通明海和英罗港高桥岸段。20 世纪 50 年代中国红树林的总面积约为 $420 \mathrm{~km}^{2}, 2001$ 年 为 $228 \mathrm{~km}^{2}$, 总体上在急剧萎缩 [29]。目前已经采取 了保护管理的多种措施。我国 1975 年以来已建立 18 个红树林自然保护区，其中国家级的有 6 个（海南 东寨港、广西北仑河口、广西山口、广东湛江、深 圳福田、福建漳江口), 保护区红树林面积已占全 国总面积一半以上。最近范航清等 [30] 报道, 国家 林业局第二次全国湿地资源调查, 2013 年红树林面 积为 $253 \mathrm{~km}^{2}$, 比 2001 年增加 $10 \%$ 以上。在全球 红树林面积逐年减少的背景下, 中国初步遏制了红 树林面积急剧下降的势头。这主要归功于政府的严 格保护政策和大规模人工造林，红树林保护和生态 修复得到国家的高度重视, 2017 年 4 月, 习总书记 视察北海金海湾红树林时指示: 一定要尊重科学, 落实责任，把红树林保护好。6 个国家级红树林自 然保护区在 “十二五” 期间各自获得的中央和地方 专项经费一般不低于 2500 万元，大力支持了红树 林恢复。我们仍然要关注我国红树林的结构与功能 退化及过度围垦造成极度缺乏适合乡土红树林生长 的潮间带宜林滩涂问题，未来增加红树林面积的主 要手段是退塘还林 [30]。 


\section{四、热带生物海岸面临的主要生态风险}

\section{（一）珊瑚礁海岸的主要生态风险}

从 20 世纪 80 年代末开始, 珊瑚礁的重要性及 其面临的危机得到普遍关注。人们关注海岸带各种 开发活动对珊瑚礁的影响, 包括沉积物污染、营养 物污染、过度捕捞、沙石采挖和围垦的直接破坏等。 1994 年 UNEP-IOC-ASPEI-IUCN 气候变化对珊瑚礁 的影响专家组认为, 人类活动是珊瑚礁危机的主要 原因, 气候变化威胁仅会发生在遥远的将来 [31]。 1998 年, 全球珊瑚礁因历史性海温升高导致严重白 化事件, “有效损失” 全球珊瑚礁 $16 \%$, 远高于历 年人类活动导致损失总和的 $10 \%$, 引起对全球变化
影响的高度重视并彻底改变了珊瑚礁保护的议程。 2015-2016 年, 延时最长、严重程度与 1998 年类 似的全球珊瑚礁白化事件（见图 1、图 2), 再次证 实全球变暖已经成为珊瑚礁可持续发展的主要威胁。 预计随着全球变暖的持续甚至增强, 珊瑚礁大规模 消失的时间或许就在 21 世纪中叶。1994 年美国等发 起成立的国际珊瑚礁倡议组织 (ICRI) 一直是最重 要的珊瑚礁管理保护国际协调机构。2011 年由科学 家和慈善机构发起的 X L Catlin 海景调查和 2017 年 发起的 50 礁倡议是珊瑚礁管理保护的最新举措 [10]。

\section{（二）红树林海岸的主要生态风险}

到目前为止, 随着人类海岸开发活动的直接

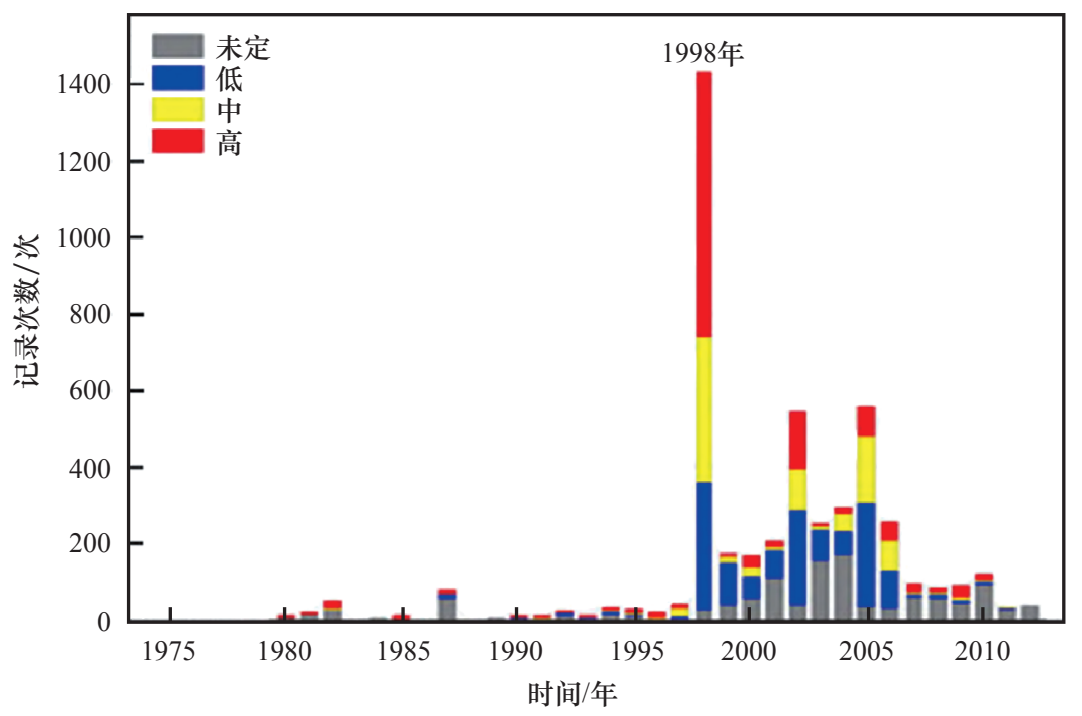

图 1 全球珊瑚礁数据库（ReefBase）不同严重程度白化记录（2010 年以后资料缺失） [10]

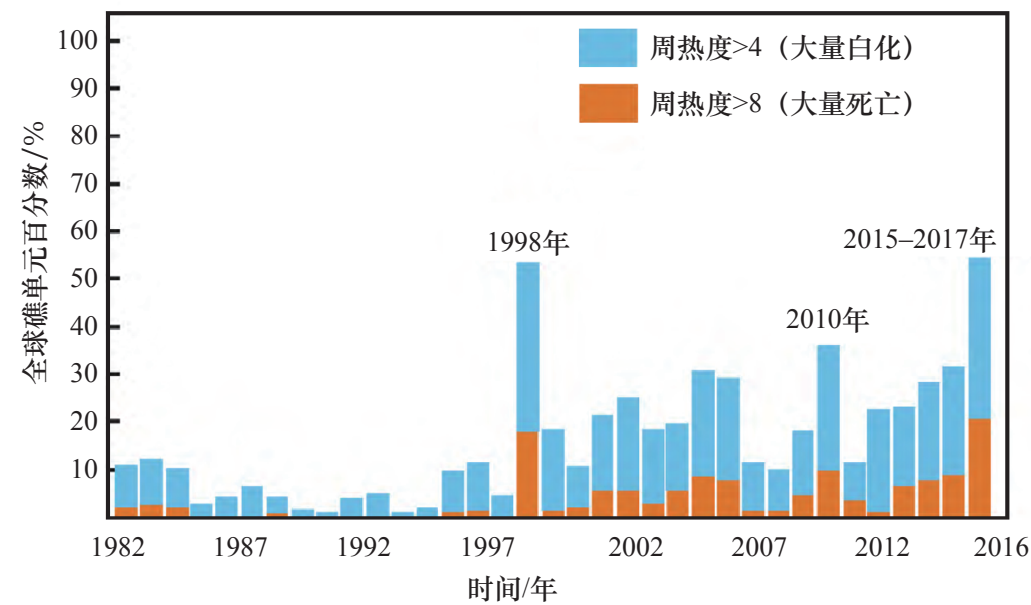

图 2 1982-2016 年美国 NOAA 卫星海温监测热压力全球礁单元百分数 [10] 
破坏和水质恶化, 水文条件改变 (如恒河三角洲红 树林区因上游建大坝导致淡水径流减少 [32]）是红 树林生态系统的最大威胁。红树林消失和生态退化 导致海岸生态关键区功能丧失, 严重削弱或丧失红 树林防浪、护岸、捕沙、促淤、维持海岸稳定的生 物地貌功能, 丧失蓝碳功能, 丧失抵消海平面上升 增加海岸带浸淹的负面影响的能力。长期以来, 人 们极端低估了红树林的价值, 忽视社会、生态与环 境效益, 一旦海岸带开发压力增大, 极易清除红树 林改作其他短期经济效益更显著的用途 [33]。人类 活动对红树林资源的影响在 20 世纪达到顶峰。从 20 世纪 80 年代起, 大规模的土地利用变化, 包括 农业围垦、鱼虾贝等水产养殖、城市向海岸发展 等, 是全球红树林消失的主要原因。21 世纪以来的 红树林损失率明显减少, 但并未停止。在短期和中 期, 随着沿海人口持续增长和海岸带持续城市化的 推动, 土地利用变化仍将是造成红树林损失的主要 原因 [25]。在人类世背景下, 海岸地区不断增加的 人类压力, 以及海平面上升和短期海平面波动的长 期威胁始终是红树林海岸的主要生态风险 [26]。

\section{五、热带生物海岸保护和发展的政策建议}

中国热带生物海岸尤其是对远海珊瑚岛礁区生 态保护和发展的建议如下。

(1) 从国家层面对保护管理战略和规划提出新 举措。在党中央、国务院关于生态文明建设的总体 部署, 和 2016 年中央深改组审议通过, 2017 年国 家海洋局印发施行的《海岸线保护与利用管理办法》 指导下, 针对热带生物海岸, 强调节能减排抑制扭 转全球变暖, 严限开发, 保护优先, 维持和增强抗 全球变化干扰和自然恢复能力。

（2）加强生态监测和开展全面调查。增加生态 监控区并扩大到南沙群岛海区, 且需要针对远海岛 礁区开展全面普查。

（3）加强保护区科学管理和建立远海大型海洋 保护区。增加完全禁止捕捞保护区的面积比例, 加 强监测评估, 提高管理成效, 把消除各种人类活动 干扰放在首要地位。

（4）针对海洋强国建设的科技需求, 加强远 海岛礁相关科学研究和人才培养。现在仍然是 “太 少的珊瑚礁科学家用太少的时间研究太少的珊瑚
礁” [34], 而且造礁石珊瑚生长在大潮低潮线以下, 绝大部分人没有机会潜水, 难以认识和研究珊瑚礁。 函需动员更多的人认识珊瑚礁、热爱珊瑚礁、研究 珊瑚礁、保护珊瑚礁。Hatcher 等 [35] 指出, 珊瑚 礁和红树林等热带浅海生态系统的未来取决于两种 速度之间的竞赛: 一是热带浅海生态系统正在加 速衰退和消失的速度, 另一个是海岸带管理模式需 在生态学和社会学上不断完善, 从公众教育方面提 高对热带浅海生态系统保护价值的认识的速度。我 国建设海洋强国战略决策和南海岛礁工程的顺利实 施, 为我国珊瑚礁研究提供了空前的发展机遇。我 们尤其要更加努力, 为海洋强国建设做出新贡献。

\section{参考文献}

[1] 张乔民. 我国热带生物海岸的现状及生态系统的修复与重建 [J]. 海洋与湖沼, 2001, 32(4): 454-465.

Zhang Q M. Status of tropical biological coasts of China: Implications on ecosystem restoration and reconstruction [J]. Oceanology et Limnologia Sinica, 2001, 32(4): 454-465.

[2] Land-Ocean Interactions in the Coastal Zone. Report of the workshop focus 2: Mangrove biogeomorphology [R]. Townsville: Land-Ocean Interactions in the Coastal Zone, 1994.

[3] Pernetta J C , Milliman J D. Land-Ocean Interaction in the Coastal Zone: Implementation plan [R]. Stockholm: IGBP, 1995.

[4] Clark J R. Coastal zone management handbook [M]. Boca Raton: CRC Press, 1996.

[5] 张乔民. 我国红树林、珊瑚礁海岸资源与开发 [R]. 香港: 香港科 技大学海岸与大气研究中心, 2000 .

Zhang Q M. Mangrove and coral reef coastal resources of China and its development [R]. Hong Kong: Centre for Coastal and Atmospheric Research, The Hong Kong University of Science and Technology, 2000.

[6] Stoddart D R. Ecology and morphology of recent coral reef [J]. Biological Review, 1969, 44: 433-498.

[7] Hopley D. Coral reefs [M]. Dordrecht: Springer, 2005.

[8] Finkl C W. Reef coasts [M]. Dordrecht: Springer, 2016.

[9] 张乔民, 余克服, 施祺, 等. 全球珊瑚礁监测与管理保护评述 [J]. 热带海洋学报, 2006, 25(2): 71-78.

Zhang Q M, Yu K F, Shi Q, et al. A review of monitoring, conservation and management of global coral reefs [J]. Journal of Tropical Oceanography, 2006, 25(2): 71-78.

[10] 张乔民, 赵美霞, 王丽荣, 等. 世界珊瑚礁现状和威胁研究进展 [J]. 广西科学, 2017, 24(5): 435-440.

Zhang Q M, Zhao M X, Wang L R, et al. A Review of current status of coral reefs and their threats in the world [J]. Guangxi Sciences, 2017, 24(5):435-440.

[11] Veron J E, Hoegh-guldberg O, Lenton T M, et al. The coral reef crisis: The critical importance of $<350 \mathrm{ppm} \mathrm{CO}_{2}[\mathrm{~J}]$. Marine Pollution Bulletin, 2009, 58(10): 1428-1436.

[12] Miller M W. Coral disturbance and recovery in a changing world [M]. Dordrecht: Springer, 2015. 
[13] Birkeland C. Coral reefs in the anthropocene [M]. Dordrecht: Springer, 2015.

[14] Wilkinson C. Status of coral reefs of the world [R]. Townsville: Global Coral Reef Monitoring Network and Reef and Rainforest Research Centre, 2008.

[15] Burke L, Reytar K, Spalding M, et al. Reefs at risk revisited [M]. Washington DC: World Resources Institute, 2011.

[16] Bellwood D R, Hughes T P, Folke C, et al. Confronting the coral reef crisis [J]. Nature, 2004, 429 (6994): 827-833.

[17] De'ath G, Fabricius K E, Sweatman H, et al. The 27-year decline of coral cover on the Great Barrier Reef and its causes [J]. Proceeding of the National Academy of Sciences, 2012, 109(44): 17995-17999.

[18] Cressey D. Terry Hughes: Reef sentinel [J]. Nature, 2016, 540: 510-511.

[19] 张乔民, 张叶春, 孙淑杰. 中国红树林和红树林海岸的现状与管 理 [C]. 中国科学院海南热带海洋生物实验站编. 热带海洋研究 (五). 北京: 科学出版社, 1997: 143-151.

Zhang Q M, Zhang Y C, Sun S J. Status and management of mangroves and mangrove coasts in China [C]. CAS HainanTropical Marine Biology Laboratory Station(Ed.). Tropical Marine Research V. Beijing: China Science Publishing \& Media Ltd., 1997: 143-151.

[20] Blasco F, Aizpuru M, Besnehard J. Mangroves, ecology [M]. Dordrecht: Springer, 2005.

[21] Blasco F, Aizpuru M. Depletion of the mangroves of Asia [J]. Wetlands Ecology and Management, 2001, 9(3): 245-256.

[22] Feller I C, Lovelock C E, Berger U, et al. Biocomplexity in mangrove ecosystems [J]. Annual Review of Marine Science, 2010, 2(1): 395-417.

[23] Duke N C, Meynecke J O, Dittmann S, et al. A world without mangroves [J]. Science, 2007, 317: 41-42.

[24] Kodikara K, Mukherjee N, Pulukkuttige J L. Have mangrove restoration projects worked? An in-depth study in Sri Lanka [J]. Restoration Ecology, 2017, 25(5): 705-716.

[25] Lewis R R, Brown B, Flynn L. Methods and criteria for successful mangrove forest rehabilitation [C]. Perillo G, et al (eds). Coastal
Wetlands: An Integrated Ecosystem Approach. 2nd Edition. Chapter 24, Singapore: Elsevier, 2019.

[26] Friess D A, Rogers K, Lovelock C E, et al. The state of the world's mangrove forests: Past, present, and future [J]. Annual Review of Environment, 2019, 44(1): 1-27.

[27] Burke L, Selig E, Spalding M. Reefs at risk in southeast Asia [M]. Washington DC: World Resources Institute, 2002.

[28] Wilkinson C R. Status of coral reefs of the world [R]. Townsville: Australian Institute of Marine Science, 2002.

[29] 廖宝文, 张乔民. 中国红树林的分布、面积和树种组成 [J]. 湿地 科学, 2014, 12(4): 435-440.

Liao B W, Zhang Q M. Area, distribution and species composition of mangroves in China [J]. Wetland Science, 2014, 12(4): 435440 .

[30] 范航清, 王文卿. 中国红树林保育若干重要问题 [J]. 厦门大学 学报(自然科学版), 2017, 56(3):323-330.

Fan H Q, Wang W Q. Some thematic issues for mangrove conservation in China [J]. Journal of Xiamen University (Natural Science), 2017, 56(3):323-330.

[31] Wilkinson C R, Buddemeier R W. Global climate change and coral reefs: Implications for people and reefs [R]. Gland: International Union for Conservation of Nature, 1994.

[32] Sarker S K, Reeve R, Thompson J, et al. Are we failing to protect threatened mangroves in the Sundarbans world heritage ecosystem [J]. Scientific Reports, 2016, 6(1): 21234.

[33] 张乔民, 隋淑珍. 中国红树林湿地资源及其保护 [J]. 自然资源 学报, 2001, 16(1): 28-36.

Zhang Q M, Sui S Z. The mangrove wetland resources and their conservation in China [J]. Journal of Natural Resources, 2001, 16(1): 28-36.

[34] Hodgson G, Liebeler J. The global coral reef crisis: Trends and solutions, 5 years of reef check (1997-2001) [R]. Los Angeles: Reef Check Foundation, 2002.

[35] Hatcher B G, Johannes R E, Robertson A I. Review of research relevant to the conservation of shallow tropical marine ecosystems [J]. Oceanography Marine Biology, 1989, 27: 337-414. 